\title{
A FUZZY APPROACH TO CONSTRUCTION PROJECT RISK ASSESSMENT.
}

\section{A. Nieto-Morote, F. Ruz-Vila}

Please cite this article in press as: Nieto-Morote, A, Ruz-Vila, F, A fuzzy approach to construction project risk assessment. Int J Project Manage (2010), doi:10.1016/j.ijproman.2010.02.002

\begin{abstract}
.
The increasing complexity and dynamism of construction projects have imposed substantial uncertainties and subjectivities in the risk analysis process. Most of the real-world risk analysis problems contain a mixture of quantitative and qualitative data; therefore quantitative risk assessment techniques are inadequate for prioritizing risks. This article presents a risk assessment methodology based on the Fuzzy Sets Theory, which is an effective tool to deal with subjective judgement, and on the Analytic Hierarchy Process (AHP), which is used to structure a large number of risks. The proposed methodology incorporates knowledge and experience acquired from many experts, since they carry out the risks identification and their structuring, and also the subjective judgements of the parameters which are considered to assess the overall risk factor: risk impact, risk probability and risk discrimination. All of these factors are expressed by qualitative scales which are defined by trapezoidal fuzzy numbers to capture the vagueness in the linguistic variables. The most notable differences with other fuzzy risk assessment methods are the use of an algorithm to handle the inconsistencies in the fuzzy preference relation when pair-wise comparison judgements are necessary, and the use of trapezoidal fuzzy numbers until the defuzzification step. An illustrative example on risk assessment of a rehabilitation project of a building is used to demonstrate the proposed methodology.
\end{abstract}

Keywords: Risk assessment; Linguistics variables; Trapezoidal fuzzy numbers; Risk factor

\section{Introduction}

According to (Mark et al., 2004), risk is simply the potential for complications and problems with respect to the completion of a project task and the achievement of a project goal. Risk is inherent in all project undertakings, as such it can never be fully eliminated, although can be effectively managed to mitigate the impacts to the achievement of project's goals.

Other definitions of risk are available in the literature such as "the exposure to the possibility of economic or financial loss or gain, physical damage or injury, or delay, as a consequence of the uncertainty associated with pursuing a particular course of action" (Perry and Hayes, 1985; Chapman and Ward, 1997), "the probability of losses in a project" (Jaafari, 2001; Kartam and Kartam, 2001), "the likelihood of a detrimental event occurring to the project" (Baloi and Price, 2003); or "a barrier to 
success" (Hertz and Thomas, 1994). Although risk has been defined in various ways, some common characteristics can be found (Chia, 2006):

- A risk is a future event that may or may not occur.

- A risk must also be an uncertain event or condition that, if it occurs, has an effect on, at least, one of the project objectives, such as scope, schedule, cost or quality.

- The probability of the future event occurring must be greater than $0 \%$ but less than $100 \%$. Future events that have a zero or $100 \%$ chance of occurrence are not risks.

- The impact or consequence of the future event must be unexpected or unplanned for.

There are many different risk sources in the construction projects and some approaches have been suggested in the literature for classifying them. Some classifications are focused on the risks nature and their magnitude (Cooper and Chapman, 1987) or on the risks origin (Edwards and Bowen, 1998; Zhou et al., 2008). Other proposals use a hierarchical structure of risks (Tah et al., 1993; Wirba et al., 1996) to classify risks according to their origin and to the location of the risk impact in the project.

The increasing size and complexity of the construction projects have added risks to their execution. With the need for improved performance in construction project and increasing contractual obligations, the requirement of an effective risk management approach has never been more necessary.

On the subject of risk management process, there have recently been a large number of researchers which have proposed different processes. Some of the most important approaches are: PRAM (Chapman, 1997), RAMP (Institution of Civil Engineering, 2002), PMBOK (Project Management Institute, 2008), RMS (Institute of Risk Management, 2002). Almost all of these approaches have a similar framework with differences in the established steps in order to get the risks control.

Effective risk management involves a four-phase process:

1. Risks identification: The process of determining which risks may affect the project and documenting their characteristics.

2. Risk assessment: The process of prioritizing risks for further analysis by assessing and combining, generally, their probability of occurrence and impact.

3. Risk response: The process of developing options and actions to enhance opportunities and to reduce threats to the project objectives.

4. Risk monitoring and reviewing: The process of implementing a risk response plan, tracking identified risks, monitoring residual risks, identifying new risks, and evaluating the risk process effectiveness throughout the project.

Risk project management is beneficial if it is implemented in a systematic manner from planning stage through the project completion. The unsystematic and arbitrary risk management can endanger the success of the project since most of the risks are very dynamic throughout the project lifetime. 


\section{Fuzzy risk assessment procedure}

The nature of construction project has imposed, in the risk analysis process, substantial uncertainties and subjectivities, which have hampered the applicability of many risk assessment methods, that are used widely in construction projects and require high quality data, such as Fault Tree Analysis (FTA), Event Tree Analysis (ETA), Probability and impact grids, Sensitivity Analysis, Estimation of System Reliability, Failure Mode and Effect Analysis (Ahmed and Amornsawadwatana, 2007).

Recently, many risk assessment approaches have been based on using linguistic assessments instead of numerical values. Using Fuzzy Sets Theory (Zadeh, 1965), data may be defined on vague, linguistic terms such as low probability, serious impact, or high risk. These terms cannot be defined meaningfully with a precise single value, but Fuzzy Sets Theory provides the means by which these terms may be formally defined in mathematical logic.

Several research studies on the risk assessment of construction projects using fuzzy approaches have been performed. Some fuzzy proposals have been inspired in the classical risk assessment methods, such as, ETA and FTA: Fujino (1994) demonstrates the applicability of the proposed fuzzy FTA methodology to some cases of construction site accidents in Japan; Huang (2001) proposes a fuzzy formal procedure in order to integrate both human-error and hardware failure events into a ETA methodology; Cho (2002) proposes a fuzzy ETA methodology characterized by the use of new forms of fuzzy membership curves.

However, the research studies have not only been focused on using fuzzy concepts into conventional risk assessment frameworks, but rather new methods have been proposed. Carr and Tah (2001) define a formal model based on a hierarchical risk breakdown structure. The risks descriptions and their consequences are defined using linguistic variables and the relationship between the likelihood of occurrence (L), the severity $(\mathrm{V})$ and the effect of a risk factor (E) is represented by rules such as "If L and V then E". Zeng et al. (2007) propose a risk assessment model based on fuzzy reasoning and AHP approach. A modified analytical hierarchy process is used to structure and prioritize risks considering three fundamental risk parameters: risk likelihood (RL), risk severity (RS) and factor index (FI), defined all of them in terms of linguistic variables which are transformed into trapezoidal fuzzy numbers. The relations between input parameters FI, RL, RS and output named Risk magnitude (RM) are presented in form of "if...then" rules. Dikmen et al. (2007) propose a methodology for risk rating of international construction projects. Once the risks have been identified and modelled using influence diagrams, they are assessed by linguistic terms. The relationships between risks and influencing factors are captured from the knowledge of experts by using "aggregation rules", where the risk knowledge is explained in form of "if...then" rules. The aggregation of fuzzy rules into a fuzzy cost overrun risk rating is carried out by fuzzy operations. Wang (2007) proposes a risk assessment methodology which allows experts to evaluate risk factors, in terms of likelihood and consequences, using linguistic terms. Also it is provided two alternative 
algorithms to aggregate the assessments of multiple risk factors, one of which offers a rapid assessment and the other one leads to an exact assessment. Zhang and Zou (2007) propose a methodology based on a hierarchical structure of risks associated with a construction project. Based on expert judgment, the weight coefficients of risk groups and risk factors are acquired with the aid of the AHP techniques and the fuzzy evaluation matrixes of risk factors. Then the aggregation of weight coefficients and fuzzy evaluation matrices produces the appraisal vector of risky conditions of the construction project.

It can be affirmed that all the proposed fuzzy risk assessment methods have a common procedure (Lyons and Skitmore, 2004):

1. Definition and measurement of parameters: The fundamental parameters, by which the risks associated with a project are assessed, are risk probability and risk severity, although other parameters can be defined. The measurement of these parameters frequently is difficult due to the great uncertainty involved. In these cases, the measurement of each parameter is made in vague data or linguistic terms and converted into its corresponding fuzzy number.

2. Definition of fuzzy inference. The relations between input parameters and output parameters can be defined in form of "if-then" rules or in form of mathematical function defined by an appropriated fuzzy arithmetic operator

3. Defuzzification. As the result of a fuzzy inference phase is a fuzzy number, this step is used to convert the fuzzy result into a exact numerical value that can adequately represent it.

In some risk assessment methodologies, some judgements are done by means of pair-wise comparisons (Zeng et al., 2007; Wang, 2007; Zhang and Zou, 2007). Preference information of alternatives generally presents inconsistency problems. Although there are a large number of studies about the inconsistency of fuzzy preference relations (Dong et al., 2008; Ghazanfari and Nojavan, 2004; M Herrera-Viedma et al. 2004; Ma et al, 2006; Wang and Chen, 2008), none of the proposed fuzzy risk assessment methodologies take into account the inconsistency of the judgements. This paper presents a fuzzy risk assessment model which most significant difference with other fuzzy risk assessment methods is the use of an algorithm to handle the inconsistencies in the fuzzy preference relation when pair-wise comparison judgements are necessary.

\section{Fuzzy sets theory}

The Fuzzy Set Theory introduced by Zadeh (1965) is suitable for dealing with imprecision and uncertainty associated with data in risk assessment problems. In a universal set of discourse X, a fuzzy subset $\mathrm{A}$ of $\mathrm{X}$ is defined by a membership function $\mu_{\mathrm{A}}(\mathrm{x})$, which maps each element $\mathrm{x}$ in $\mathrm{X}$ to a real number in the interval $[0,1]$. The function value of $\mu_{\mathrm{A}}(\mathrm{x})$ signifies the grade of membership of $\mathrm{x}$ in $\mathrm{A}$. When $\mu_{\mathrm{A}}(\mathrm{x})$ is large, its grade of membership of $\mathrm{x}$ in A is strong (Kaufmann and Gupta, 1991). 
Among the various types of fuzzy sets of special significance are fuzzy numbers (Dubois and Prade, 1978) defined as $\mathrm{A}=\left\{\mathrm{x}, \mu_{\mathrm{A}}(\mathrm{x})\right\}$ where $\mathrm{x}$ takes its number on the real line $\mathbb{R}$ and membership function $\mu_{\mathrm{A}}: \mathbb{R} \rightarrow[0,1]$, which have the following properties:

- A continuous mapping from $\mathbb{R}$ to the closed interval $[0,1]$,

- Constant on $(-\infty, \mathrm{a}]: \mu_{\mathrm{A}}(\mathrm{x})=0 \quad \forall \mathrm{x} \in(-\infty, \mathrm{a}]$,

- Strictly increasing on $[a, b]$

- Constant on $[\mathrm{b}, \mathrm{c}]: \mu_{\mathrm{A}}(\mathrm{x})=1 \quad \forall \mathrm{x} \in[\mathrm{b}, \mathrm{c}]$,

- Strictly decreasing on [c, d],

- Constant on $[\mathrm{d}, \infty): \mu_{\mathrm{A}}(\mathrm{x})=0 \quad \forall \mathrm{x} \in[\mathrm{d}, \infty)$,

where, $\mathrm{a} b, \mathrm{c}, \mathrm{d}$ are real numbers and eventually $\mathrm{a}=-\infty$, or $\mathrm{b}=\mathrm{c}$, or $\mathrm{a}=\mathrm{b}$, or $\mathrm{c}=\mathrm{d}$ or $\mathrm{d}=\infty$.

For convenience, $\mu^{\mathrm{L}}$ is named as left membership function of a fuzzy number $\mathrm{A}$, defining $\mu^{\mathrm{L}} \mathrm{A}(\mathrm{x})=$ $\mu_{\mathrm{A}}(\mathrm{x})$, for all $\mathrm{x} \in[\mathrm{a}, \mathrm{b}] ; \mu^{\mathrm{R}}{ }_{\mathrm{A}}$ is named as right membership function of a fuzzy number $\mathrm{A}$, defining $\mu^{\mathrm{R}} \mathrm{A}(\mathrm{x})=\mu_{\mathrm{A}}(\mathrm{x})$, for all $\mathrm{x} \in[\mathrm{c}, \mathrm{d}]$.

A trapezoidal fuzzy number $A$ is a fuzzy number denoted as $A=(a, b, c, d)$ which membership function is defined as:

$\mu_{A}(x)=\left[\begin{array}{cll}0 & \text { for } x<a \\ \mu_{A}^{L}(x)=\frac{x-a}{b-a} & \text { for } a \leq x \leq b \\ 1 & \text { for } b \leq x \leq c \\ \mu^{R}{ }_{A}(x)=\frac{x-d}{c-d} & \text { for } c \leq x \leq d \\ 0 & \text { for } x>d\end{array}\right.$

where $a, b, c$ and $d$ are real numbers and $a<b<c<d$. If $b=c$, it is defined a triangular fuzzy number.

By the extension principle (Zadeh, 1965), the fuzzy arithmetic operations of any two trapezoidal fuzzy numbers follow these operational laws:

Fuzzy addition:

$\mathrm{A}_{1} \oplus \mathrm{A}_{2}=\left(\mathrm{a}_{1}+\mathrm{a}_{2}, \mathrm{~b}_{1}+\mathrm{b}_{2}, \mathrm{c}_{1}+\mathrm{c}_{2}, \mathrm{~d}_{1}+\mathrm{d}_{2}\right)$

Fuzzy subtraction:

$A_{1} \Theta A_{2}=\left(a_{1}-d_{2}, b_{1}-c_{2}, c_{1}-b_{2}, d_{1}-a_{2}\right)$

Fuzzy multiplication:

$\mathrm{A}_{1} \otimes \mathrm{A}_{2} \approx\left(\mathrm{a}_{1} \times \mathrm{a}_{2}, \mathrm{~b}_{1} \times \mathrm{b}_{2}, \mathrm{c}_{1} \times \mathrm{c}_{2}, \mathrm{~d}_{1} \times \mathrm{d}_{2}\right)$

Fuzzy division:

$\mathrm{A}_{1} \oslash \mathrm{A}_{2} \approx\left(\mathrm{a}_{1} / \mathrm{d}_{2}, \mathrm{~b}_{1} / \mathrm{c}_{2}, \mathrm{c}_{1} / \mathrm{b}_{2}, \mathrm{~d}_{1} / \mathrm{a}_{2}\right)$ 
The fuzzy addition or the fuzzy subtraction of any two fuzzy trapezoidal numbers is also a trapezoidal fuzzy number. But the fuzzy multiplication or the fuzzy division is only approximate a trapezoidal fuzzy number.

The scalar multiplication of a trapezoidal fuzzy number is also a trapezoidal fuzzy number defined as:

$\mathrm{k} \times \mathrm{A}=(\mathrm{k} \times \mathrm{a}, \mathrm{k} \times \mathrm{b}, \mathrm{k} \times \mathrm{c}, \mathrm{k} \times \mathrm{d})$ if $\mathrm{k}>0$

$\mathrm{k} \times \mathrm{A}=(\mathrm{k} \times \mathrm{d}, \mathrm{k} \times \mathrm{c}, \mathrm{k} \times \mathrm{b}, \mathrm{k} \times \mathrm{a})$ if $\mathrm{k}<0$

\subsection{The algebraic operations of fuzzy numbers based on $\alpha$-cut concept.}

The $\alpha$-cuts of a fuzzy number A with membership function $\mu_{\mathrm{A}}(\mathrm{x})$ are defined as the crisp set that contains all the elements of $\mathbb{R}$ whose membership grades in A are greater or equal to the specified value of $\alpha$ :

$\mathrm{A}^{\alpha}=\left\{\mathrm{x} \mid \mu_{\mathrm{A}}(\mathrm{x}) \geq \alpha, \quad 0 \geq \alpha \geq 1\right\}$

and denoted it by $\left[\mathrm{A}_{1}^{\alpha}, \mathrm{A}_{\mathrm{r}}{ }^{\alpha}\right]$, i.e., $\mathrm{A}^{\alpha}=\left[\mathrm{A}_{\mathrm{l}}{ }^{\alpha}, \mathrm{A}_{\mathrm{r}}{ }^{\alpha}\right]$.

The multiplication and division operations on closed intervals, $\mathrm{A}^{\alpha}=\left[\mathrm{A}_{1}{ }^{\alpha}, \mathrm{A}_{\mathrm{r}}{ }^{\alpha}\right]$ and $\mathrm{B}^{\alpha}=\left[\mathrm{B}_{1}{ }^{\alpha}, \mathrm{B}_{\mathrm{r}}{ }^{\alpha}\right]$, are defined as (Klir and Yuan, 1995):

Multiplication:

$(A \times B)^{\alpha}=\left\lfloor A^{\alpha}{ }_{1} \times B^{\alpha}{ }_{1}, A^{\alpha}{ }_{r} \times B^{\alpha}{ }_{r}\right\rfloor$

Division:

$(A \div B)^{\alpha}=\left\lfloor A^{\alpha}{ }_{1} / B^{\alpha}{ }_{r}, A^{\alpha}{ }_{r} / B^{\alpha}{ }_{1}\right\rfloor$

According the extension principle (Zadeh, 1965), an arbitrary fuzzy set A can fully and uniquely be represented as:

$\mathrm{A}=\underset{\alpha \in[0,1]^{\alpha}-\mathrm{A}^{\alpha}(\mathrm{x})}{ }$

where $U$ denotes the standard fuzzy union and $\alpha \_A^{\alpha}$ denotes the special fuzzy set which membership function is defined as:

$\mu_{\alpha \_\mathrm{A}_{\alpha}}= \begin{cases}\alpha & \text { for } \mathrm{x} \in \mathrm{A}^{\alpha} \\ 0 & \text { for } \mathrm{x} \notin \mathrm{A}^{\alpha}\end{cases}$

Therefore, the multiplication and division operations of any two positive fuzzy numbers A and B, which $\alpha$-cuts are denoted as $\mathrm{A}^{\alpha}=\left[\mathrm{A}^{\alpha}{ }_{1}, \mathrm{~A}_{\mathrm{r}}^{\alpha}\right]$ and $\mathrm{B}^{\alpha}=\left[\mathrm{B}^{\alpha}{ }_{1}, \mathrm{~B}_{\mathrm{r}}^{\alpha}\right]$ respectively, can be expressed as:

Fuzzy multiplication

$\mathrm{A} \otimes \mathrm{B}=\bigcup_{\alpha \in[0,1]^{\alpha-}(\mathrm{A} \times \mathrm{B})^{\alpha}(\mathrm{x})}$ 
Fuzzy division

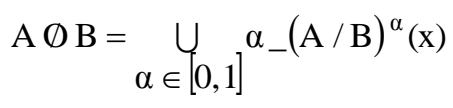

\section{Proposed risk assessment model}

A risk assessment model, based on fuzzy reasoning, is proposed as shown in Fig. 1. The model consists of three steps: preliminary step, definition of risk factor function and measurement of variables step and fuzzy inference step. The details are described in the following sections.

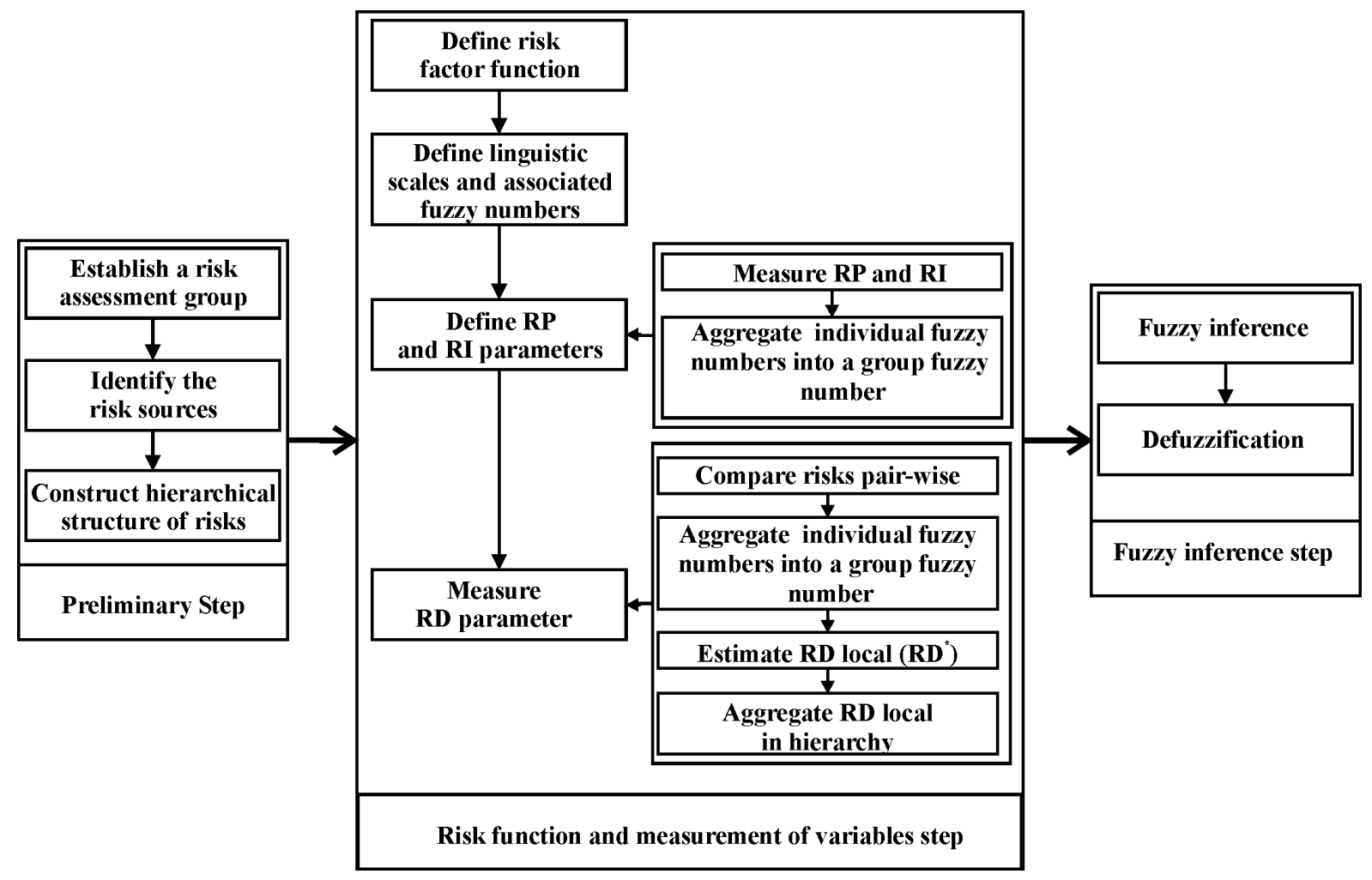

Fig. 1. Fuzzy assessement model.

\subsection{Preliminary step}

\subsubsection{Establish a risk assessment group}

The members in a risk assessment group must be carefully selected. The selected experts will have a high degree of knowledge and previous experience in similar construction projects. The risk assessment team must include the following experts: project managers, project team members, customers, subject matter experts from outside the project team, end users, stakeholders and risk management group. 
The members in the risk assessment group will undertake the risk identification, even though all project personnel should be encouraged to identify risks. Also, the risk assessment group will undertake the measure of risk function parameters.

\subsubsection{Identify the risk sources}

Risk identification is studying a situation to realize what could go wrong in the project development at any given point of time during the project. The process must involve an investigation into all the potential sources of project risks and their consequences. It is of considerable importance because the process of risk analysis and response strategies may only be performed on the identified potential risks.

The risks identification is an iterative process because the risks may evolve or new risks become known as the project progresses through its life cycle. The iteration frequency and who participate in each cycle will depend on the characteristics of the project.

The experts in a risk assessment group have intuitive methods of recognizing a risk situation. Anyway, there are some risks identification tools as: Checklist, Influence Diagrams, Cause and Effect Diagrams, Failure Mode and Effect Analysis, Hazard and Operability Study, Fault Trees and Event Tree (Ahmed and Amornsawadwatana, 2007).

\subsubsection{Construct hierarchical structure of risks}

The members in the risk assessment group are required to identify and classify the risks associated with the construction project. To decompose the risks into adequate details in which they can be efficiently assessed, a hierarchical structure of risks is generated. The risks are sorted into $\mathrm{n}$ groups on the basis of the types of risks, as shown in Fig. 2. More levels of decomposition can be incorporated into the hierarchical structure whenever the elements of a given level are mutually independent, but comparable to the elements of the same level.

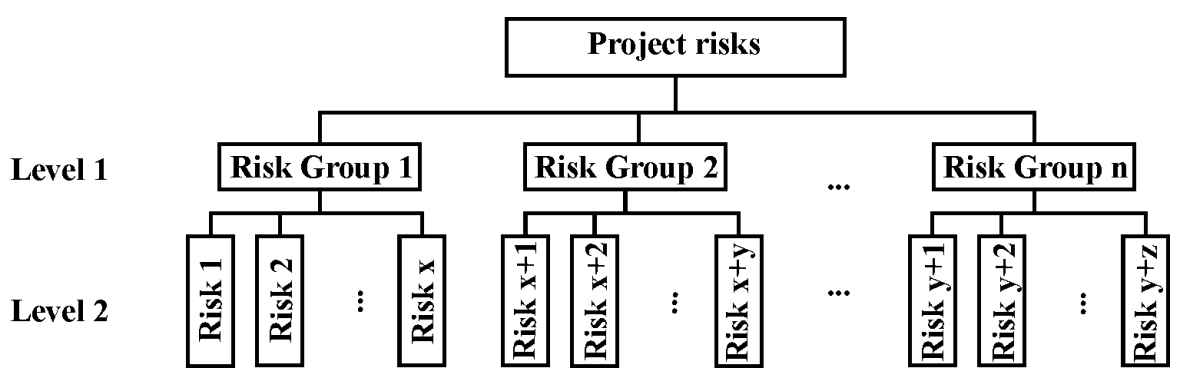

Fig. 2. Generic hierarchical structure of risks. 


\subsection{Definition of risk factor function and measurement of variables step}

\subsubsection{Define risk factor function}

The risk factor (RF) can usually be assessed by considering two fundamental risk parameters: risk impact (RI) and risk probability (RP). The risk impact parameter investigates the potential effect of the risk on a project objective such as schedule, cost, quality or performance. The risk probability parameter investigates the likelihood that each specific risk will occur. These parameters do not take into consideration the impact of the risk to the overall framework of the project. In order to assess the risks efficiently and effectively, a parameter, named risk discrimination (RD), is proposed (Cervone, 2006). The risk discrimination parameter provides an additional perspective because it gauges the impact of the risk to the overall framework of the project, rather than looking at each risk as an independent variable within the project. With each risk evaluated in the context of the three dimensions, a value can be assigned to each risk using Eq. (14):

Overall Risk Factor $=\frac{\text { Risk Impact } \mathrm{x} \text { Risk probability }}{\text { Risk discrimination }}$

\subsubsection{Define linguistic scales and associated fuzzy numbers}

Frequently, it may be extremely difficult to assess the risk associated with a project due to the great uncertainty involved. The imprecision comes from a variety of sources such as, unquantifiable information, incomplete information or non-obtainable information (Chen and Hwang, 1992). When the members in a risk assessment group have inexact information about risks associated with a project, the assessments can not be exact but approximate. In these circumstances, the judgements of the members in a risk assessment group are expressed by means of linguistic term instead of real numbers.

An important aspect to handle this kind of problems is to define the linguistic terms that will be used. The possible linguistic terms that can be used depends on the nature of the problem. The linguistic terms which generally can be used to assess the parameters of a risk assessment problem, risk impact, risk probability and risk discrimination are the following ones:

- For evaluating the first dimension, RI, a five-point scale is defined: Critical (C), Serious (S), Moderate (Mo), Minor (Mi) and Negligible (N).

- For the second dimension, RP, a three-point scale is proposed: High (H), Medium (M) and Low probability (L).

- The third parameter, RD, will be obtained by pair-wise comparison between risks. The selected comparison scale is: Much less (Ml), Less (L), Same (S), More (M) and Much more (Mm).

The linguistics terms must be transformed into a fuzzy numbers by using appropriate conversion scale. One of the key points in fuzzy modelling is the definition of fuzzy numbers which represent vague concepts and imprecise terms expressed in a natural language. The representation does not only 
depend on the concept but also on the context in which it is used. Even for similar contexts, fuzzy numbers representing the same concept may vary considerably.

When operating with fuzzy numbers, the result of our calculations strongly depend on the shape of the membership functions of these numbers. Less regular membership functions lead to more complicated calculations. Moreover, fuzzy numbers with simpler shape of membership functions often have more intuitive and more natural interpretation.

All these reasons cause a natural need of simple approximations of fuzzy numbers which are easy to handle and have a natural interpretation. For the sake of simplicity the trapezoidal or triangular fuzzy numbers are most common in current applications. As noted in a research study (Mayor and Trillas, 1986), the precision in the shape of the membership functions often is not important because of the quantitative nature of the problems with vague predicates; thus they are generally written as linearly as possible. Normally it is sufficient to use a trapezoidal representation, as it makes it possible to define them with no more than four parameters.

Based on some researches, a numerical approximation system is proposed to systematically convert linguistic terms into their corresponding fuzzy numbers (Chen and Hwang, 1992). The used linguistic terms, their meaning and their associated membership function are shown in Table 1.

Table 1

Descriptions of RI, RP and RD comparison

\begin{tabular}{lll}
\hline Description of RI & General interpretation & Fuzzy number \\
\hline Critical (C) & Involved very highly impact & $(0.8,0.9,1,1)$ \\
Serious (S) & Involved highly impact & $(0.6,0.75,0.75,0.9)$ \\
Moderate (Mo) & Involved moderate impact & $(0.3,0.5,0.5,0.7)$ \\
Minor (Mi) & Involved only small impact & $(0.1,0.25,0.25,0.4)$ \\
Negligible (N) & Involved no substantive impact & $(0,0,0.1,0.2)$ \\
& & \\
Description of RP & General interpretation & $(0.7,0.9,1,1)$ \\
\hline High (H) & Very likely to occur & $(0.2,0.5,0.5,0.8)$ \\
Medium (M) & Likely to occur & $(0,0,0.1,0.2)$ \\
Low (L) & Occurrence is unlikely & \\
Description of RDC & General interpretation & $(0,0,0,0.3)$ \\
\hline Much more & Much more impact on overall framework of project than & $(0,0.25,0.25,0.5)$ \\
More & More impact on overall framework of project than & $(0.3,0.5,0.5,0.7)$ \\
Same & Same impact on overall framework of project than & $(0.5,0.75,0.75,1)$ \\
Less & Less impact on overall framework of project than \\
Much Less & Much less impact on overall framework of project than & $(0.7,1,1,1)$ \\
\hline
\end{tabular}

\subsubsection{Define of RI and RP parameters}

\subsubsection{Measure RI and RP}

The RI and RP parameters of each risk at the bottom level of the hierarchy must be measured by each member in the risk assessment group using the defined linguistic scales. The linguistic measures for RI and RP assigned by each member in the group are converted into their corresponding fuzzy 
numbers according to Table 1. The fuzzy numbers obtained for RI and RP parameters are $\mathrm{RI}_{\mathrm{i}}^{\mathrm{m}}$ and $\mathrm{RP}_{\mathrm{i}}^{\mathrm{m}}$ where $\mathrm{i}$ is the number of risks at the bottom level of the hierarchy and $\mathrm{m}$ is the number of members in risk assessment group.

\subsubsection{Aggregate individual fuzzy numbers into a group fuzzy number}

The individual fuzzy numbers $\mathrm{RI}_{\mathrm{i}}{ }^{\mathrm{m}}$ and $\mathrm{RP}_{\mathrm{i}}{ }^{\mathrm{m}}$, corresponding to each one of the $\mathrm{m}$ expert in the risk assessment group, are aggregated into group fuzzy number by using the fuzzy arithmetic average, which is defined as:

$$
\begin{aligned}
& \mathrm{RI}_{\mathrm{i}}=\frac{1}{\mathrm{~m}} \times \sum_{\mathrm{n}=1}^{\mathrm{m}} \mathrm{RI}_{\mathrm{i}}{ }^{\mathrm{n}}=\frac{1}{\mathrm{~m}} \times\left(\mathrm{RI}_{\mathrm{i}}{ }^{1} \oplus \mathrm{RI}_{\mathrm{i}}{ }^{2} \oplus \cdots \oplus \mathrm{RI}_{\mathrm{i}}^{\mathrm{m}}\right) \\
& \mathrm{RP}_{\mathrm{i}}=\frac{1}{\mathrm{~m}} \times \sum_{\mathrm{n}=1}^{\mathrm{m}} \mathrm{RP}_{\mathrm{i}}{ }^{\mathrm{n}}=\frac{1}{\mathrm{~m}} \times\left(\mathrm{RP}_{\mathrm{i}}{ }^{1} \oplus \mathrm{RP}_{\mathrm{i}}{ }^{2} \oplus \cdots \oplus \mathrm{RP}_{\mathrm{i}}^{\mathrm{m}}\right)
\end{aligned}
$$

where $i$ is each one of the risks at the bottom level of the hierarchy, $m$ is the number of members in risk assessment group, $x$ is the scalar multiplication defined in Eq. (6) and $\oplus$ is the fuzzy addition defined in Eq. (2).

\subsubsection{Measure RD parameter}

\subsubsection{Compare risks pair-wise}

The members in the risk assessment group are required to provide their comparative judgement on the impact on overall framework of the project for each risk pair-wise of the same level and group in the hierarchical structure.

These linguistic measures are converted into their corresponding fuzzy members according to Table 1. For each member in risk assessment group it is obtained the following comparison matrix for the group $g$ and the level 1 in the hierarchy:

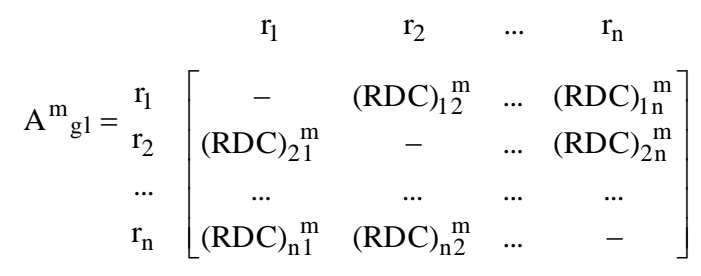

where $\mathrm{n}$ is the number of risks of the group $\mathrm{g}$ and the level 1 in the hierarchy and $\mathrm{m}$ is the number of members in risk assessment group.

\subsubsection{Aggregate individual fuzzy numbers into a group fuzzy number}

The comparative fuzzy numbers of each one of the members in the risk assessment group are aggregated into a group fuzzy number by using the fuzzy arithmetic average which is defined as: 


$$
\mathrm{RDC}_{\mathrm{ij}}=\frac{1}{\mathrm{~m}} \times \sum_{\mathrm{n}=1}^{\mathrm{m}} \mathrm{RDC}_{\mathrm{ij}}{ }^{\mathrm{n}}=\frac{1}{\mathrm{~m}} \times\left(\mathrm{RDC}_{\mathrm{ij}}{ }^{1} \oplus \mathrm{RDC}_{\mathrm{ij}}{ }^{2} \oplus \cdots \oplus \mathrm{RDC}_{\mathrm{ij}} \mathrm{m}^{\mathrm{j}}\right)
$$

where $\mathrm{i}$ and $\mathrm{j}$ are the risks of the group $\mathrm{g}$ and the level 1 in the hierarchy and $\mathrm{m}$ is the number of members in risk assessment group, $x$ is the scalar multiplication defined in Eq. (6) and $\oplus$ is the fuzzy addition defined in Eq. (2).

The matrix for the group $g$ and the level 1 in the hierarchy of comparative fuzzy numbers is defined as:

$$
\begin{gathered}
\mathrm{A}_{\mathrm{gl}}= \\
\mathrm{r}_{1} \\
\mathrm{r}_{2} \\
\ldots \\
\mathrm{r}_{\mathrm{n}}
\end{gathered}\left[\begin{array}{cccc}
\mathrm{r}_{2} & \ldots & \mathrm{r}_{\mathrm{n}} \\
(\mathrm{RDC})_{21} & (\mathrm{RDC})_{12} & \ldots & (\mathrm{RDC})_{1 \mathrm{n}} \\
\ldots & - & \ldots & (\mathrm{RDC})_{2 \mathrm{n}} \\
(\mathrm{RDC})_{\mathrm{n} 1} & (\mathrm{RDC})_{\mathrm{n} 2} & \ldots & -
\end{array}\right]
$$

where $\mathrm{n}$ is the number of risks of the group $\mathrm{g}$ and the level 1 in the hierarchy.

\subsubsection{Estimate RD local $\left(R D^{*}\right)$}

This problem is solved by using fuzzy classical methods of criteria weight calculation adapted to operate with trapezoidal fuzzy numbers.

In the fuzzy classical methods, the decision maker (DM) provides its fuzzy preference relations on criteria pair-wise, $\mathrm{W}_{\mathrm{ij}}$. The ratio $\mathrm{W}_{\mathrm{ij}}$ denotes the preference degree of the criteria $\mathrm{c}_{\mathrm{i}}$ over $\mathrm{c}_{\mathrm{j}}$ and it is usually defined as a fuzzy singleton, which is a fuzzy set which contains only one element.

If values of the fuzzy preference relations on criteria pair-wise were consistent, $\mathrm{W}{ }_{\mathrm{ij}}$, by the reciprocal property of fuzzy preference relation, i.e., $\mathrm{W}^{\prime}{ }_{\mathrm{ij}}+\mathrm{W}^{\prime}{ }_{\mathrm{ji}}=1$, there would be an explicit functional relation between $\mathrm{W}^{\prime}{ }_{\mathrm{ij}}$ and the fuzzy values $\mathrm{w}_{\mathrm{i}}$ and $\mathrm{w}_{\mathrm{j}}$, which would reflect the ranking values of the criteria $\mathrm{c}_{\mathrm{i}}$ and $c_{j}$ (Ma et al. 2006):

$$
\mathrm{W}^{\prime}{ }_{\mathrm{ij}}=0.5 \times\left\lfloor 1+\psi\left(\mathrm{w}_{\mathrm{i}}\right)-\psi\left(\mathrm{w}_{\mathrm{j}}\right)\right\rfloor
$$

where $\psi\left(\mathrm{w}_{\mathrm{i}}\right)$ can be any non-decreasing function and $\sum \mathrm{w}_{\mathrm{i}}=1$.

By the reciprocal property of preference of the values $W^{\prime}{ }_{i j}$, the Eq (20) satisfies the additive transitivity property, i.e., $\mathrm{W}^{\prime}{ }_{\mathrm{ik}}+\mathrm{W}^{\prime}{ }_{\mathrm{ik}}+\mathrm{W}^{\prime}{ }_{\mathrm{ki}}=1.5$

In order to keep the simplicity of the method, if $\psi\left(\mathrm{w}_{\mathrm{i}}\right)=\mathrm{w}_{\mathrm{i}}$ then $\mathrm{Eq}(20)$ is transformed into a new equation defined as:

$$
\mathrm{W}^{\prime}{ }_{\mathrm{ij}}=\frac{\mathrm{W}_{\mathrm{i}}+\left(1-\mathrm{w}_{\mathrm{j}}\right)}{2}
$$

Generally the pair-wise comparison information given by the DM has inconsistency, that is $\mathrm{W}_{\mathrm{ik}}<0.5$ for $\mathrm{W}_{\mathrm{ij}} \geq 0.5$ and $\mathrm{W}_{\mathrm{jk}} \geq 0.5$. Transitivity is the property that is usually accepted to deal with problems of fuzzy preference relations consistency (Wang and Chen, 2008, Dong et al., 2008). 
Due to the fuzziness of the opinions and the weak transitivity restriction considered, that is, $\mathrm{W}_{\mathrm{ik}} \geq 0.5$ for $\mathrm{W}_{\mathrm{ij}} \geq 0.5$ and $\mathrm{W}_{\mathrm{jk}} \geq 0.5$ (Herrera-Viedma et al. 2004), an accurate solution for this problem could not be found. The $\mathrm{w}_{\mathrm{i}}$ and $\mathrm{w}_{\mathrm{j}}$ values are calculated by difference minimization method of the value $\mathrm{W}_{\mathrm{ij}}$, obtained directly from the experts, and the value $\mathrm{W}^{\prime}{ }_{\mathrm{ij}}$, defined as a ideal fuzzy preference relations which are consistent:

$$
\min \left[\sum_{\mathrm{i}=1}^{\mathrm{n}} \sum_{\substack{\mathrm{j}=1 \\ \mathrm{i}=1}}^{\mathrm{n}}\left(\mathrm{W}^{\mathrm{i}}{ }_{\mathrm{ij}}-\mathrm{W}_{\mathrm{ij}}\right)^{2}\right]
$$

In our case, the values of fuzzy preference relations on risks obtained directly from the experts, $\mathrm{RDC}_{\mathrm{ij}}$, and the values of the ideal fuzzy preference relations on risks, which are consistent, $\mathrm{RDC}_{\mathrm{ij}}$, are trapezoidal fuzzy numbers. The extension of this classical method to fuzzy method can be expressed as:

$$
\min \left[\sum_{\substack{\mathrm{i}=1 \\ \mathrm{j}=1}}^{\mathrm{n}=1} \sum_{\mathrm{i}=1}^{\mathrm{n}}\left(\operatorname{RDC}^{\prime}{ }_{\mathrm{ij}} \Theta \operatorname{RDC}_{\mathrm{ij}}\right)^{2}\right]
$$

where $\mathrm{RDC}^{\prime}{ }_{\mathrm{ij}}$ is defined in terms of the fuzzy values of $\mathrm{RD}^{*}{ }_{\mathrm{i}}$ and $\mathrm{RD}_{\mathrm{j}}{ }_{\mathrm{j}}$, which reflect the ranking values of the risks $r_{i}$ and $r_{j}$, as:

$$
\mathrm{RDC}^{\prime}{ }_{\mathrm{ij}}=\frac{\mathrm{RD}_{\mathrm{i}}^{*} \oplus\left(1 \Theta \mathrm{RD}_{\mathrm{j}}^{*}\right)}{2}
$$

where $\mathrm{i}$ and $\mathrm{j}$ are risks of the group $\mathrm{g}$ and the level 1 in the hierarchy and $\oplus$ and $\Theta$ represents the fuzzy addition and subtraction using Eqs. (2) and (3).

The main implication of this method is that the sum of $\mathrm{RD}^{*}{ }_{\mathrm{i}}$ should be now a trapezoidal fuzzy number "around one" that must be defined correctly to get a solution.

The matrix for the group $g$ and the level 1 in the hierarchy of the RD* fuzzy values are defined as:

$$
\mathrm{B}_{\mathrm{gl}}=\begin{gathered}
\mathrm{r}_{1} \\
\mathrm{r}_{2} \\
\ldots \\
\mathrm{r}_{\mathrm{n}}
\end{gathered}\left[\begin{array}{c}
\mathrm{RD}^{*}{ }_{1} \\
\mathrm{RD}_{2}{ }_{2} \\
\mathrm{RD}^{*}{ }_{\mathrm{n}}
\end{array}\right]
$$

where $\mathrm{n}$ is the number of risks of the group $\mathrm{g}$ and the level 1 in the hierarchy.

\subsubsection{Aggregate $R D^{*}$ in hierarchy}

Assume the risk $r_{i}$ has $t$ upper groups at different level in the risk structure hierarchy and $\mathrm{RD}^{*}{ }^{*}{ }_{\text {group }}$ is the value $\mathrm{RD}^{*}$ of the $\mathrm{j}^{\text {th }}$ upper group which contain the risk $r_{i}$ in the hierarchy. The final value of $\mathrm{RD}$ for each risk $r_{i}$ can be calculated by: 


$$
\mathrm{RD}_{\mathrm{i}}=\mathrm{RD}_{\mathrm{i}}^{*} \otimes \prod_{\mathrm{j}=1}^{\mathrm{t}}\left(\mathrm{RD}^{*}\right)_{\text {group }}^{(\mathrm{j})}
$$

where $i$ is each one of the risks at the bottom level of the hierarchy and $\otimes$ represent the fuzzy multiplication using arithmetic operations on their $\alpha$-cuts in Eq. (12).

\subsection{Fuzzy inference step}

In the fuzzy inference step, risk analysts convert the aggregated fuzzy number of RI, RP and RD into a fuzzy number that represents the overall risk factor of each risks $r_{i}$.

\subsubsection{Fuzzy inference}

Once the RI, RP and RD parameters are expressed by trapezoidal fuzzy numbers, the overall risk factor is calculated as

$$
\mathrm{ORF}_{1}=\left(\mathrm{RI}_{\mathrm{i}} \otimes \mathrm{RP}_{\mathrm{i}}\right) \emptyset \mathrm{RD}_{\mathrm{i}}
$$

where $\mathrm{i}$ is each one of the risks at the bottom level of the hierarchy and $\otimes$ and $\emptyset$ represent the fuzzy multiplication and the fuzzy division using arithmetic operations on their $\alpha$-cuts in Eqs. (12) and (13), respectively.

\subsubsection{Defuzzification}

Defuzzification of fuzzy numbers is an important procedure for the risk assessment in fuzzy environment. Defuzzification is the operation of producing a non-fuzzy number, a single value that adequately represents the fuzzy number ORF.

There are several methods proposed for defuzzification process. In this research, the centroid method (Yager, 1980) is proposed according to the requirements for reflecting the real situation and the viewpoint of the assessment group.

$$
\left(\mathrm{ORF}_{\mathrm{T}}\right)_{i}=\frac{\int_{0}^{1} \mathrm{x} \operatorname{ORF}_{\mathrm{i}}(\mathrm{x}) \mathrm{d}(\mathrm{x})}{\int_{0}^{1} \mathrm{ORF}_{\mathrm{i}}(\mathrm{x}) \mathrm{d}(\mathrm{x})}
$$

where $\mathrm{i}$ is each one of the risks at the bottom level of the hierarchy.

The output of the fuzzy risk assessment procedure is a final risk rating.

\section{Numerical example}

A case example of risk assessment on the rehabilitation project of a building in University of Cartagena is presented to demonstrate the applicability of the proposed risk assessment methodology. 
According to the project requirements, the project duration is identified as a critical objective. Therefore, the time overrun is identified as a major risk which needs to be assessed for securing the success of the project.

There are many risk sources which can lead to the delay of the project completion, such as, lack of supply quality, design changes, lack of resources, etc. This kind of risks is difficult to measure due to the lack of information and uncertainties involved. As there are no adequate practical data and information to support a traditional risk analysis, the proposed risk assessment method has been employed to assess the risks of the completion of a rehabilitation project.

\subsection{Establish a risk assessment group}

Four experts with high experience in rehabilitation projects of buildings are selected to form the risk assessment group. The risk assessment team is formed by a civil engineer, an architect, an archaeologist and a project manager, all of them experts in rehabilitation of buildings. The team undertakes the risk assessment by using the proposed methodology.

\subsection{Identify the risk sources and construct hierarchical structure of risks}

On the basis of their experience and qualification, the risk assessment group identifies the risks and constructs a risk hierarchy as shown in Fig.3. The defined hierarchy consists of four groups i.e. 'engineering risks', 'execution risks', 'suppliers risks' and 'project management risks'. For example, under project management group, there are four major risks will affect the completion of the rehabilitation project. They are 'Lack of adequate process', 'Lack of resources', 'Inexperienced team members' and 'Lack of motivation attitudes'.

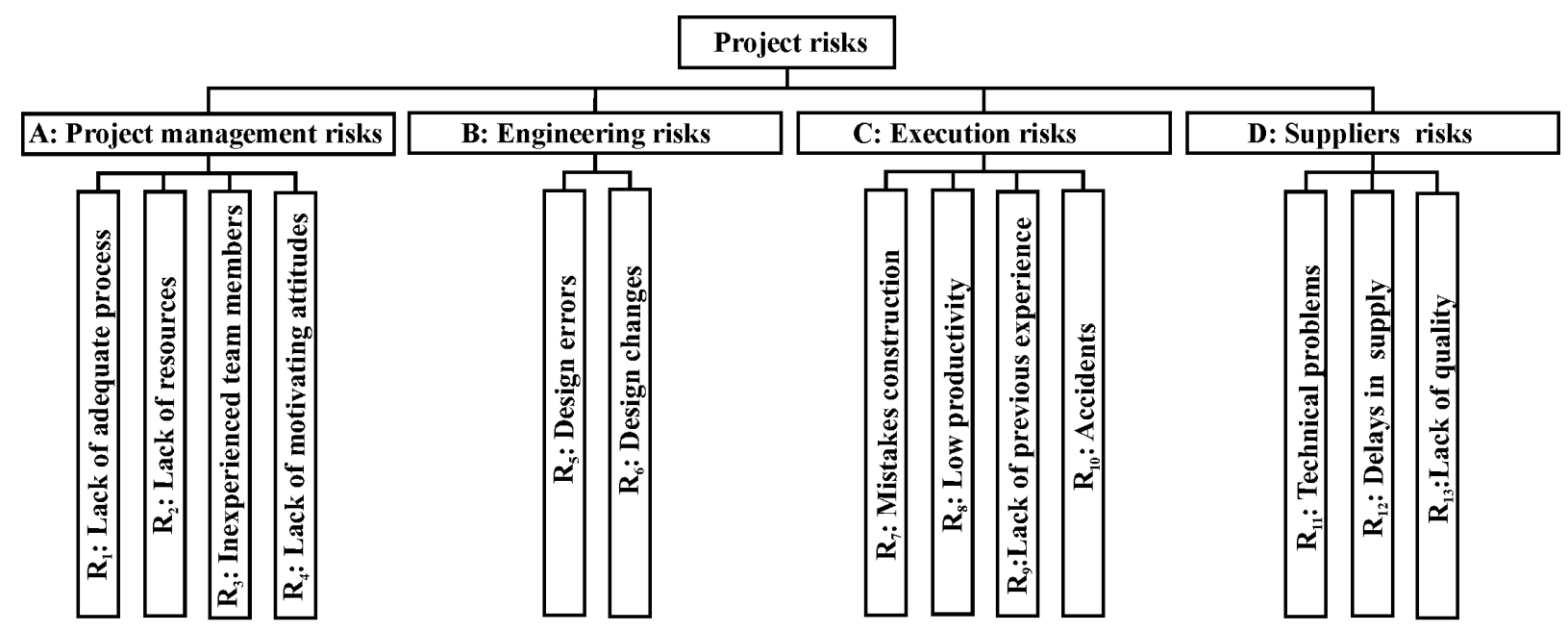

Fig. 3. Hierarchical structure of risks. 
5.3. Measure of RI and RP parameters and aggregate individual fuzzy numbers into group fuzzy number

The measurement of RI and RP for each risk at the bottom level of the hierarchy, involves the following steps: (a) linguistic measure of RI and RP by each expert using the linguistic terms shown in Table 1, (b) convert these measures into fuzzy numbers using the score system shown in Table 1 (c) and aggregate the fuzzy numbers into a group fuzzy number by applying the fuzzy arithmetic average as shown Eqs. (15) and (16), respectively. As example, the fuzzy numbers corresponding to the linguistics measurement of RI and RP of the risks under 'project management group' and their group values are shown in Table 2.

Table 2

Membership functions of RI and RP parameters and fuzzy aggregation

\begin{tabular}{llll}
\hline Risks & & Measure of RI & Measure of RP \\
\hline Lack of adequate process & E1 & $(0.1,0.25,0.25,0.4)$ & $(0,0,0.1,0.2)$ \\
& E2 & $(0,0,0.1,0.2)$ & $(0,0,0.1,0.2)$ \\
& E3 & $(0.3,0.5,0.5,0.7)$ & $(0.2,0.5,0.5,0.8)$ \\
& E4 & $(0.6,0.75,0.75,0.9)$ & $(0.2,0.5,0.5,0.8)$ \\
& Ag. & $(0.2500,0.3750,0.4000,0.5000)$ & $(0.1000,0.2500,0.3000,0.5000)$ \\
Lack of resources & E1 & $(0,0,0.1,0.2)$ & $(0.2,0.5,0.5,0.8)$ \\
& E2 & $(0.3,0.5,0.5,0.7)$ & $(0,0,0.1,0.2)$ \\
& E3 & $(0.3,0.5,0.5,0.7)$ & $(0.7,0.9,1,1)$ \\
& E4 & $(0.1,0.25,0.25,0.4)$ & $(0.2,0.5,0.5,0.8)$ \\
& Ag. & $(0.1750,0.3125,0.3375,0.5000)$ & $(0.2750,0.4750,0.5250,0.7000)$ \\
Inexperienced team members & E1 & $(0.3,0.5,0.5,0.7)$ & $(0.2,0.5,0.5,0.8)$ \\
& E2 & $(0.6,0.75,0.75,0.9)$ & $(0.2,0.5,0.5,0.8)$ \\
& E3 & $(0.3,0.5,0.5,0.7)$ & $(0,0,0.1,0.2)$ \\
& E4 & $(0.6,0.75,0.75,0.9)$ & $(0.2,0.5,0.5,0.8)$ \\
& Ag. & $(0.4500,0.6250,0.6250,0.8000)$ & $(0.1500,0.3750,0.4000,0.6500)$ \\
& E1 & $(0.3,0.5,0.5,0.7)$ & $(0.2,0.5,0.5,0.8)$ \\
& E2 & $(0.1,0.25,0.25,0.4)$ & $(0.7,0.9,1,1)$ \\
& E3 & $(0.3,0.5,0.5,0.7)$ & $(0.7,0.9,1,1)$ \\
& E4 & $(0.6,0.75,0.75,0.9)$ & $(0.7,0.9,1,1)$ \\
& Ag. & $(0.3250,0.5000,0.5000,0.6750)$ & $(0.5750,0.8000,0.8750,0.9500)$ \\
\hline
\end{tabular}

\subsection{Measure of RD parameter}

5.4.1. Compare risk factors pair-wise and aggregate individual fuzzy numbers into group fuzzy number

For every risk pair-wise in each group and level defined in the hierarchy, each member in the risk assessment group provides its comparative judgement on the impact on overall framework of the project using the linguistic terms shown in Table 1. Each one of the comparative judgements, which is provided by the members in the risk assessment group, is converted into its corresponding fuzzy number using the score system shown in Table 1. As example, the fuzzy numbers corresponding to compare judgement of each pair-wise risks under project management group and their corresponding 
group fuzzy numbers calculated by applying the fuzzy arithmetic averaging defined in Eq. (18) are shown in Table 3.

Table 3

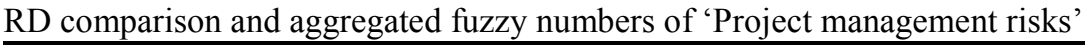

\begin{tabular}{|c|c|c|c|c|c|}
\hline $\begin{array}{l}\text { Project } \\
\text { manageme } \\
\text { nt risks }\end{array}$ & & Lack of adequate process & Lack of resources & $\begin{array}{l}\text { Inexperienced team } \\
\text { members }\end{array}$ & $\begin{array}{l}\text { Lack of motivation } \\
\text { attitudes }\end{array}$ \\
\hline $\begin{array}{l}\text { Lack of } \\
\text { adequate } \\
\text { process }\end{array}$ & $\begin{array}{l}\text { E1 } \\
\text { E2 } \\
\text { E3 } \\
\text { E4 } \\
\text { Ag. }\end{array}$ & - & $\begin{array}{l}(0,0,0,0.3) \\
(0,0.25,0.25,0.5) \\
(0,0,0,0.3) \\
(0,0.25,0.25,0.5) \\
\quad(0,0.125,0.125,0.4)\end{array}$ & $\begin{array}{l}(0,0.25,0.25,0.5) \\
(0.3,0.5,0.5,0.7) \\
(0.3,0.5,0.5,0.7) \\
(0,0.25,0.25,0.5) \\
\quad(0.15,0.375,0.375,0.6)\end{array}$ & $\begin{array}{l}(0,0.25,0.25,0.5) \\
(0,0.25,0.25,0.5) \\
(0,0.25,0.25,0.5) \\
(0,0.25,0.25,0.5) \\
\quad(0,0.25,0.25,0.5)\end{array}$ \\
\hline $\begin{array}{l}\text { Lack of } \\
\text { resources }\end{array}$ & $\begin{array}{l}\text { E1 } \\
\text { E2 } \\
\text { E3 } \\
\text { E4 } \\
\text { Ag. }\end{array}$ & $\begin{array}{l}(0.7,1,1,1) \\
(0.5,0.75,0.75,1) \\
(0.7,1,1,1) \\
(0.5,0.75,0.75,1) \\
\quad(0.6,0.875,0.875,1)\end{array}$ & - & $\begin{array}{l}(0.5,0.75,0.75,1) \\
(0.5,0.75,0.75,1) \\
(0.5,0.75,0.75,1) \\
(0.5,0.75,0.75,1) \\
\quad(0.5,0.75,0.75,1)\end{array}$ & $\begin{array}{l}(0.5,0.75,0.75,1) \\
(0.3,0.5,0.5,0.7) \\
(0.3,0.5,0.5,0.7) \\
(0.5,0.75,0.75,1) \\
(0.4,0.625,0.625,0.85)\end{array}$ \\
\hline $\begin{array}{l}\text { Inexperien } \\
\text { ced team } \\
\text { members }\end{array}$ & $\begin{array}{l}\text { E1 } \\
\text { E2 } \\
\text { E3 } \\
\text { E4 } \\
\text { Ag. }\end{array}$ & $\begin{array}{l}(0.5,0.75,0.75,1 \\
(0.3,0.5,0.5,0.7) \\
(0.3,0.5,0.5,0.7) \\
(0.5,0.75,0.75,1) \\
(0.4,0.625,0.625,0.85)\end{array}$ & $\begin{array}{l}(0,0.25,0.25,0.5) \\
(0,0.25,0.25,0.5) \\
(0,0.25,0.25,0.5) \\
(0,0.25,0.25,0.5) \\
\quad(0,0.25,0.25,0.5)\end{array}$ & - & $\begin{array}{l}(0,0.25,0.25,0.5)) \\
(0.3,0.5,0.5,0.7)) \\
(0.3,0.5,0.5,0.7)) \\
(0,0.25,0.25,0.5) \\
(0.15,0.375,0.375,0.6)\end{array}$ \\
\hline $\begin{array}{l}\text { Lack of } \\
\text { motivation } \\
\text { attitudes }\end{array}$ & $\begin{array}{l}\text { E1 } \\
\text { E2 } \\
\text { E3 } \\
\text { E4 } \\
\text { Ag. }\end{array}$ & $\begin{array}{l}(0.5,0.75,0.75,1) \\
(0.5,0.75,0.75,1) \\
(0.5,0.75,0.75,1) \\
(0.5,0.75,0.75,1) \\
\quad(0.5,0.75,0.75,1)\end{array}$ & $\begin{array}{l}(0,0.25,0.25,0.5) \\
(0.3,0.5,0.5,0.7) \\
(0.3,0.5,0.5,0.7) \\
(0,0.25,0.25,0.5) \\
(0.15,0.375,0.375,0.6)\end{array}$ & $\begin{array}{l}(0.5,0.75,0.75,1) \\
(0.3,0.5,0.5,0.7) \\
(0.3,0.5,0.5,0.7) \\
(0.5,0.75,0.75,1) \\
\quad(0.4,0.625,0.625,0.85)\end{array}$ & - \\
\hline
\end{tabular}

\subsubsection{Calculate $R D^{*}$ value}

For the elements of each group and level, the values of $\mathrm{RD}^{*}{ }_{\mathrm{i}}$ are calculated by using Eqs (23) and (24). The values of $\mathrm{RD}_{\mathrm{i}}^{*}$ corresponding to the risks of all the groups and levels in the hierarchy are shown in Table 4.

Table 4

Values of RD, ORF and $\mathrm{ORF}_{\mathrm{T}}$

\begin{tabular}{|c|c|c|c|c|c|}
\hline Risks & $\mathrm{RD}^{*}$ & $\mathrm{RD}$ & ORF & $\mathrm{ORF}_{\mathrm{T}}$ & Ranking \\
\hline A & $(0.0700,0.1200,0.1400,0.1900)$ & & & & \\
\hline $\mathrm{R}_{1}$ & $(0.0700,0.100,0.1300,0.1500)$ & $(0.0099,0.0197,0.0301,0.0423)$ & $(0.0065,0.0544,0.1222,1.2320)$ & 0.6369 & 1 \\
\hline $\mathrm{R}_{2}$ & $(0.4765,0.5185,0.5565,0.6065)$ & $(0.0676,0.1021,0.1291,0.1710)$ & $(0.0031,0.0201,0.0348,0.2303)$ & 0.1934 & 7 \\
\hline $\mathrm{R}_{3}$ & $(0.0900,0.1352,0.1742,0.2042)$ & $(0.0128,0.0266,0.0404,0.0576)$ & $(0.0128,0.1016,0.1883,1.8119)$ & 0.5977 & 2 \\
\hline $\mathrm{R}_{4}$ & $(0.2335,0.2593,0.2893,0.3293)$ & $(0.0331,0.0511,0.0671,0.0928)$ & $(0.0220,0.1044,0.1718,0.8612)$ & 0.0508 & 10 \\
\hline B & $(0.1200,0.1700,0.2000,0.2400)$ & & & & \\
\hline $\mathrm{R}_{5}$ & $(0.0750,0.2500,0.2500,0.5000)$ & $(0.0053,0.0300,0.0350,0.0950)$ & $(0.0363,0.2888,0.4385,7.2472)$ & 0.3183 & 3 \\
\hline $\mathrm{R}_{6}$ & $(0.5300,0.7500,0.7500,0.9000)$ & $(0.0371,0.0900,0.1050,0.1710)$ & $(0.0239,0.1050,0.1584,1.0540)$ & 0.2460 & 5 \\
\hline $\mathrm{C}$ & $(0.3481,0.3991,0.4381,0.4881)$ & & & & \\
\hline $\mathrm{R}_{7}$ & $(0.0700,0.1220,0.1680,0.2100))$ & $(0.0084,0.0207,0.0336,0.0504)$ & $(0.0406,0.2266,0.4531,3.9401)$ & 0.1106 & 9 \\
\hline $\mathrm{R}_{8}$ & $(0.5444,0.5994,0.6244,0.6344)$ & $(0.0653,0.1019,0.1249,0.15239$ & $(0.0032,0.0219,0.0369,0.2725)$ & 0.0426 & 12 \\
\hline $\mathrm{R}_{9}$ & $(0.1256,0.1686,0.2156,0.2556)$ & $(0.0151,0.0287,0.0431,0.0613)$ & $(0.0258,0.1326,0.2524,1.7567)$ & 0.0406 & 13 \\
\hline $\mathrm{R}_{10}$ & $(0.0700,0.1240,0.1720,0.2000)$ & $(0.0084,0.0211,0.0344,0.0480)$ & $(0.0086,0.0549,0.1783,1.8078)$ & 0.1806 & 8 \\
\hline $\mathrm{D}$ & $(0.1419,0.1969,0.2319,0.2819)$ & & & & \\
\hline $\mathrm{R}_{11}$ & $(0.0800,0.1230,0.1450,0.1700)$ & $(0.0278,0.0491,0.0635,0.0830)$ & $(0.0074,0.0482,0.0842,0.6112)$ & 0.0450 & 11 \\
\hline $\mathrm{R}_{12}$ & $(0.5067,0.5300,0.5650,0.5933)$ & $(0.1764,0.2115,0.2475,0.2896)$ & {$\left[\begin{array}{lllll}0.0068 & 0.0254 & 0.0385 & 0.1514\end{array}\right]$} & 0.2742 & 4 \\
\hline $\mathrm{R}_{13}$ & $(0.2733,0.3000,0.3250,0.3466)$ & $(0.0951,0.1197,0.1424,0.1692)$ & {$\left[\begin{array}{llll}0.0029 & 0.0192 & 0.0314 & 0.1871\end{array}\right]$} & 0.1978 & 6 \\
\hline
\end{tabular}




\subsubsection{Aggregate $R D^{*}$ in hierarchy}

For each risk $r_{i}$ at the bottom level of the hierarchy, the value $\mathrm{RD}_{\mathrm{i}}$ is calculated using Eq. (26). The obtained values are shown in Table 4.

\subsection{Fuzzy inference step}

\subsubsection{Calculate $O R F$}

Once all parameters RI, RP and RD are valued in form of fuzzy numbers, the overall risk factor of each risk at the bottom level of the hierarchy is calculated using Eq.(27). The obtained values are shown in Table 4.

\subsubsection{Defuzzification}

The last step is to convert the fuzzy output ORF of each risk at the bottom level of the hierarchy into a numerical value $\mathrm{ORF}_{\mathrm{T}}$ by using the defuzzification operator as defined in Eq. (28). The obtained values are shown in Table 4.

\subsection{Results}

The application of this risk assessment methodology to the case on the rehabilitation project of a building in University of Cartagena leads to the following conclusions. The members in the risk assessment group have identified 13 risks classified into four groups as shown in Fig.3. The cost of the process of development of actions to reduce threats to the project objectives is very high. For this reason, the process of prioritizing risks is crucial. An improvement of the project performance is possible when the actions of the plan risk responses are focused on high-priority risks.

Without forgetting that all the identified risks can affect the project, starting from the results presented in the last column of Table 4, it can be affirmed that the actions of plan risk response must fundamentally be focused on the risks 'Lack of adequate process' 'Inexperienced team members', 'Design error' and 'Delay in supply'. These data demonstrate that project management team must be paid special attention to the composition of the risk assessment group and its activities.

\section{Conclusion}

Project risk management is a necessary and critical task of the project manager and project team. Understanding risk management entails understanding the underlying factors that contribute to project risks, which are often the same regardless of the nature of the project. The first step in risk assessment is risk identification. Once risk identification is complete, risk analysis is used to identify the likelihood the risks that have been identified will happen. The ranking of risks is necessary because it 
would be difficult, if not impossible, to provide a plan for dealing with every possible risk in every step of the project. With a risk factor value assigned to each risk, the team now has a roadmap for mitigating project risk by developing contingency plans only for the tasks that have the highest risk factor.

In many circumstances, the application of classical risk assessment methodologies may not give satisfactory results due to incomplete risk data or the high level of uncertainty involved in the risk data available. It is therefore essential to develop new risk analysis methods to assess the risks in conditions of project execution where classical methods cannot be efficiently applied.

This paper presents a new methodology for construction project risk analysis to deal with risks associated with the construction projects in the complicated situations in which the information to assess risks is unquantifiable, incomplete or non-obtainable.

The approach allows members in the risk assessment group to make their judgements by means of linguistic terms instead of real numbers. Since linguistic terms are not mathematically operable, to cope with difficulty, each linguistic term is associated with a trapezoidal fuzzy number, which represents the meaning of each verbal term.

In order to facilitate the application of this methodology to problems with a large number of risks, a hierarchical weighting method to assess the weight of risks using pair-wise comparisons has been developed. The risk pair-wise comparative judgements are generally not consistent. The weighting method included an algorithm to reduce the inconsistency of the comparative judgement based on the minimization of the difference between the value of preference judgement obtained directly from the members in the risk assessment group and the ideal consistent value. This is a very important aspect in order to avoid misleading solutions.

To illustrate how the approach works, a problem on risk assessment of a rehabilitation project of a building has been presented.

The approach provides a simple and effective mechanism for modelling risk assessment problems involving subjective evaluations of the members in the risk assessment group. The developed methodology is applicable to the general fuzzy risk assessment problem where a ranking of risks is required.

\section{References}

Ahmed, A., Kayis, B., Amornsawadwatana, S., 2007. A review of techniques for risk management in projects. Benchmarking 14, 22-36.

Baloi, D., Price, A.D.F., 2003. Modelling global risk factors affecting construction cost performance. International Journal of Project Management 21, 261-269.

Carr, V., Tah, J.H.M., 2001. A fuzzy approach to construction project risk assessment and analysis: construction project risk management system. Advances in engineering software 32, 847-857. 
Cervone, H.F., 2006. Project Risk management. OCLC Systems \& Services 22, 256-262.

Chapman, C., 1997. Project risk analysis and management- the PRAM generic process. International Journal of Project Management 15, 273-281.

Chapman, C.B., Ward, S.C., 1997. Project risk management: Processes, Techniques and Insights. Wiley.

Chen, S.J., Hwang, C.L., 1992. Fuzzy multiple attribute decision making: methods and applications. Springer-Verlag, 465-474.

Chia, S.E., 2006. Risk assessment framework for Project Management. IEEE 376-379.

Cho, H.M., Choia, H.H., Kimb, Y.K., 2002. A risk assessment methodology for incorporating uncertainties using fuzzy concepts Reliability Engineering and System Safety 78, 173-183.

Cooper, D.F., Champan, C.B., 1987. Risk analysis for Large Project. Wiley, Chichester.

Dikmen, I., Birgonul, M., Han, S., 2007. Using fuzzy risk assessment to rate cost overrun risk in international construction projects. International Journal of Project Management 25, 494-505.

Dong, Y., Xu, Y., Li, H., 2008. On consistency measures of linguistic preference relations. European Journal of Operational Research 189, 430-444.

Dubois, D., Prade, H., 1978. Operations on fuzzy numbers. International Journal of Systems Science 9, 613-626.

Edwards, P.J., Bowen, P.A., 1998. Risk and risk management in construction: a review and future directions for research. Engineering construction and Architectural Management 5, 339-349.

Fujino, T., 1994. The development of a method for investigation construction site accidents using fuzzy fault tree analysis. PhD Thesis. The Ohio State University, USA.

Ghazanfari, M., Nojavan, M., 2004. Reducing inconsistency in fuzzy AHP by mathematical programming models. Asia - Pacific Journal of Operational Research, 21, 379-391.

Herrera-Viedma, E. Herrera , F. Chiclana, F. Luque, M, 2004 Some issues on consistency of fuzzy preference relations. European Journal of Operational Research 154, 98-109.

Hertz, D.B., Thomas, H., 1994. Risk Analysis and its Applications. John Wiley \& Son, Detroit.

Huang, D., Chen, T., Wang, M.J.J., 2001. A fuzzy set approach for event tree analysis. Fuzzy Sets and Systems 118, 153-65.

Institute of Risk Management, 2002. A risk management. Standard Institute of Risk Management.

Institution of Civil Engineers, 2002. Risk Analysis and Management for Projects (RAMP). Institution of Civil Engineers and Faculty and Institute of Actuaries. Thomas Telford, London.

Jaafari, A., 2001. Management of risk, uncertainties and opportunities on projects: time for a fundamental shift. International Journal of project management 19, 89-101.

Kartam, N.A., Kartam S.A., 2001. Risk and its management in the Kuwaiti construction industry: a contactors' perspective. International Journal of project management 19, 325-335.

Kaufmann, A., Gupta, M.M., 1991. Introduction to fuzzy arithmetic: Theory and Application. Van Nostrand Reinhold, New York. 
Klir, J.k., Yuan, B., 1995. Fuzzy sets and fuzzy logic. Theory and applications. Prentice Hall, New Jersey, 102-104.

Ma, J., Fan, Z.P., Jiang, Y.P., Mao, J.Y., Ma, L., 2006. A method for repairing the inconsistency of fuzzy preference relations. Fuzzy sets and systems 157, 20-33.

Mark, W., Cohen, P.E., Glen, R.P., 2004. Project risk identification and management. AACE International Transaction. INT.01.1-5.

Mayor, Trillas, E.,1986. On the representation of some aggregation functions, Proc. 16th ISMVL, Blacksburg ·pp. 110-114.

Lyons, T., Skitmore, M., 2004. Project risk management in the Queensland engineering construction industry: a survey. International Journal of project management 22, 51-61.

Perry, J.G., Hayes, R.W., 1985. Risk and its management in construction projects. Proceeding of Institution Civil Engineers, 499-521.

Project Management Institute, 2008. A guide to the project management body of knowledge. Project Management Institute Standards Committee.

Tah, J.H.M., Thorpe, A., McCaffer, R., 1993. Contactor project risks contingency allocation using linguistic approximation. Computing system in Engineering 4, 281-293

Wang, T.C., Chen, Y.H., 2008. Applying fuzzy linguistic preference relations to the improvement of consistency of fuzzy AHP. Information Sciences 178 , 3755-3765.

Wang, Y.M., Elhag T.M-S., 2007. A fuzzy group decision making approach for bridge risk assessment. Computers \& Industrial Engineering 53, 137-148

Wirba, E.N., Tah, J.H.M., Howes, R., 1996. Risk interdependencies and natural language computations. Journal of Engineering, Construction and Architectural Management 3, 251-269.

Yager, R.R., 1980. On a general class of fuzzy connectives. Fuzzy sets \& Systems 4, 235-242.

Zadeh, L.A., 1965. Fuzzy sets. Information Control 8, 338-353.

Zeng, J., An, M., Smith, N.J., 2007. Application of a fuzzy based decision making methodology to construction project risk assessment. International Journal of Project Management 27, 589-600.

Zhang, G., Zou, P.X.W., 2007. Fuzzy analytical hierarchy process risk assessment approach for joint venture construction projects in China. Journal of Construction Engineering and Management 133, 771-779

Zhou, L., Vasconcelos, A., Numes, M., 2008. Supporting decision making in risk management through an evidence-based information systems Project risk checklist. Information management \& computer security 16, 166-186 